32

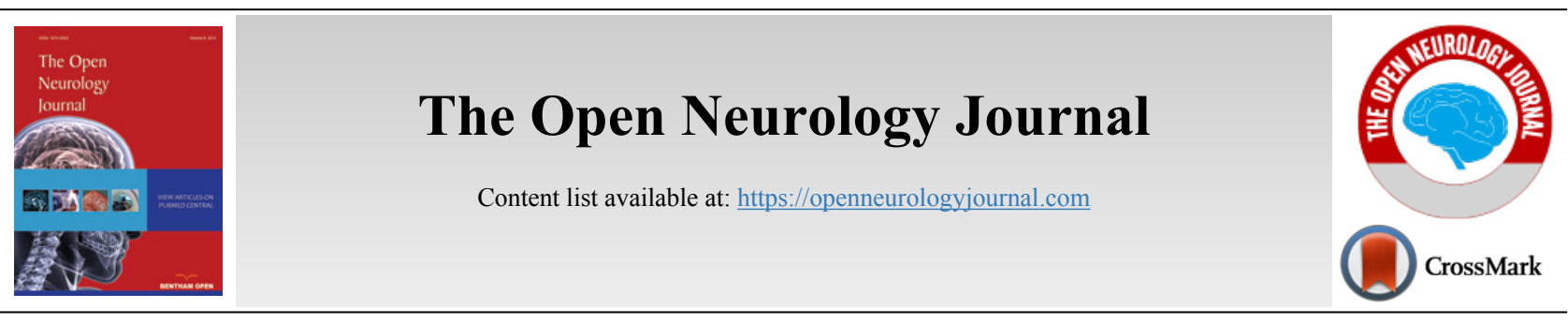

SYSTEMATIC REVIEW

\title{
Botulinum Toxin for the Treatment of Focal Task-Specific Hand Dystonias: Systematic Review and Meta-Analysis
}

Nigel Ashworth ${ }^{1}$, Henry Aidoo ${ }^{2}$, Alexander Doroshenko ${ }^{2}$, David Antle ${ }^{3}$, Charl Els ${ }^{4}$, David Mark Flaschner ${ }^{5}$, Douglas P. Gross $^{6}$, Christine Guptill ${ }^{7}$, Patrick Potter ${ }^{8}$, Maria C. Tan ${ }^{9}$ and Sebastian Straube,

${ }^{\prime}$ Division of Physical Medicine \& Rehabilitation, Department of Medicine, University of Alberta, Edmonton, Alberta, T6G 2T4, Canada

${ }^{2}$ Division of Preventive Medicine, Department of Medicine, University of Alberta, Edmonton, Alberta, T6G 2T4, Canada

${ }^{3}$ Faculty of Medicine and Dentistry, University of Alberta, Edmonton, Alberta, T6G 2T4, Canada

${ }^{4}$ Department of Psychiatry, University of Alberta, Edmonton, Alberta, T6G 2T4, Canada

${ }^{5}$ Department of Physical Medicine \& Rehabilitation, University of Calgary, Calgary, Alberta, Canada

${ }^{6}$ Department of Physical Therapy, University of Alberta, Edmonton, Alberta, T6G 2T4, Canada

${ }^{7}$ Department of Occupational Therapy, University of Alberta, Edmonton, Alberta, T6G 2T4, Canada

${ }^{8}$ Parkwood Institute, London, Ontario, Canada

${ }^{9} J o h n$ W. Scott Health Sciences Library, University of Alberta, Edmonton, Alberta, T6G 2T4, Canada

\begin{abstract}
:
Objective:

Botulinum Toxin (BTX) has become a widely used treatment in several dystonic conditions, but the evidence for its efficacy has largely come from open trials and expert opinion. This systematic review examined the efficacy and safety of BTX in the treatment of Focal Hand Dystonia (FHD) in Randomized Controlled Trials (RCTs).

Methods:

We searched Ovid MEDLINE, EMBASE, Cochrane Database of Systematic Reviews (CDSR), Database of Abstracts of Reviews of Effects (DARE), Cochrane Central Register of Controlled Trials (CENTRAL), CINAHL, SPORT Discus, SCOPUS, Web of Science, PEDro, ClinicalTrials.gov, and the International Clinical Trials Registry Platform (ICTRP) for randomized, placebo-controlled trials on the use of BTX for FHD.

Results:

Of 1,116 publications retrieved from the databases searched, three publications were included. The evidence identified pertains to focal taskspecific hand dystonias. Sixty-nine participants were involved in the three RCTs with a mean duration of symptoms of 7.5 years. Participants were assessed using a combination of self-reported and functional performance outcome measures following injections of BTX subtype A (BTX-A) or placebo. The Oxford Quality Scale was used to assess the included studies, and the three studies each scored 3/5 or above. The included studies reported no adverse events with BTX-A use, other than muscle weakness and pain at the injection sites.
\end{abstract}

\section{Conclusion:}

The number of participants included in these three trials is too small to draw dependable conclusions about the efficacy and safety of BTX-A for FHD. There is currently not enough evidence to recommend the routine use of BTX-A for FHD.

Keywords: Botulinum toxin, Clinical trials, Dystonia, Meta-analysis, Systematic review, Focal hand dystonia.

Article History Received: October 19, 2018 Revised: January 17, 2019 Accepted: February 04, 2019

\section{INTRODUCTION}

Dystonia is a disabling neurological syndrome that can produce involuntary, sustained or spasmodic movements and abnormal postures $[1,2]$. The pathophysiology of dystonia is complex and it seems likely that dysfunction in the basal ganglia or linked central pathways leads to abnormal motor output from the central nervous system. Complex movements, such as writing or playing the piano, can be particularly affected. Focal Hand Dystonia (FHD) manifests as a loss of 
motor control while performing a specific skilled repetitive hand action (e.g. musician's dystonia, writer's cramp). Such movements require exquisite motor control with excitatory and inhibitory signals controlling appropriate muscle contractions whilst simultaneously relaxing surrounding muscles. This "surround inhibition" is abnormal in patients with dystonia with both agonist and antagonist muscles in a limb segment cocontracting [3].

Botulinum Toxin (BTX) may help patients with dystonia by weakening specific overactive muscles, but there is often a fine balance between making a muscle too weak and not weakening it enough. While the use of BTX in other types of dystonia such as cervical dystonia is supported by a larger evidence base with respect to efficacy, evidence reviews for the use of BTX as a treatment for FHD are limited [4, 5]. An upto-date knowledge synthesis on the use of BTX for FHD has the potential to impact clinical decision making and guideline development.

The objective of this systematic review is to summarize the current literature relating to the efficacy and safety of BTX in the treatment of FHD as assessed in Randomized Controlled Trials (RCTs).

\section{METHODS}

This systematic review followed the recommendations outlined in the Preferred Reporting Items for Systematic Reviews and Meta-Analyses (PRISMA) statement [6].

\subsection{Criteria for Study Inclusion}

In order to be eligible for inclusion, clinical trials needed to be randomized, double-blind, and placebo-controlled. The treatment group should have received BTX and the control group an inactive sham or placebo. Participants needed to have a clinical diagnosis of FHD and should not have undergone specific additional treatment for their dystonia as part of the trial.

\subsection{Searching}

A systematic literature search was conducted by a health sciences librarian (MCT) using the following databases:

- $\quad$ Ovid MEDLINE® Epub Ahead of Print, In-Process \& Other Non-Indexed Citations, Daily and 1946 to present

- Ovid Embase 1974 to present

- Wiley Cochrane Library: Cochrane Database of Systematic Reviews (CDSR)

- Wiley Cochrane Library: Database of Abstracts of Reviews of Effects (DARE)

- Wiley Cochrane Library: Cochrane Central Register of Controlled Trials (CENTRAL)

- EBSCOHost CINAHL Plus with Full Text 1937 to present

\footnotetext{
* Address correspondence to this author at the Division of Preventive Medicine, Department of Medicine, University of Alberta, 5-30 University Terrace, 8303 -112 Street NW, Edmonton, Alberta, T6G 2T4, Canada; Tel: +1 780492 6291; Fax: +1 780492 9677; E-mail: straube@ualberta.ca
}

- $\quad$ EBSCOHost SPORT Discus with Full Text

- SCOPUS

- Web of Science Core Collection

- PEDro Physiotherapy Evidence Database

An auxiliary search was also conducted in the following clinical trial registries:

- ClinicalTrials.gov

- World Health Organization International Clinical Trials Registry Platform (ICTRP)

All searches were conducted between September 28 and 29, 2017. The MEDLINE search strategy was developed by MCT and then was peer-reviewed by a librarian expert searcher at the University of Alberta. The MEDLINE search strategy was then translated to search strategies suitable for the other databases.

The search strategy included a combination of controlled vocabulary terms (e.g., Medical Subject Headings (MeSH) and keywords representing the concepts of "hand dystonia" and "botulinum toxin". The full search strategy for all the databases searched is available in Appendix A of this publication. A search filter was applied for RCTs and to reduce retrieval of animal studies, when feasible. No language, date, or other limits were applied in the electronic database searches. Additional references were identified in the following ways: by hand-searching reference lists of all included studies as well as pertinent review articles; by forward citation searching in Scopus to find studies citing any of the included articles; and by searching conference proceedings for abstracts, posters and presentations on FHD and BTX treatment. Results were exported to the RefWorks citation management system [7] and subsequently imported into Covidence [8], which was used for deduplication, as well as title/abstract, and full-text screening. Three authors (DA, AD, and HA) duplicated the title/abstract and full-text screening; while data extraction was performed in duplicate by CG, DG, and HA. Disagreements would have been resolved by SS.

\subsection{Study Quality Assessment}

For the assessment of risk of bias, all eligible trials were assessed using a three-item, five-point scale, the Oxford Quality Scale [9], that considers randomization, blinding, study withdrawals and dropouts, and a consensus score was agreed upon. Each study was assessed in duplicate (CG, DG and HA). Disagreements were resolved by SS.

\subsection{Outcomes}

Our primary outcome of interest was hand function as measured by any validated hand function assessment at two weeks to two months post-treatment.

Our secondary outcomes included:

[1] Any validated assessment of hand function at two to six months post-treatment

[2] Reduction in secondary symptoms (e.g. pain, tremor)

[3] Any assessment of quality of life 
Table 1. Characteristics of included studies.

\begin{tabular}{|c|c|c|c|c|c|c|}
\hline $\begin{array}{c}\text { First Author and } \\
\text { Year }\end{array}$ & Type of Study & $\begin{array}{l}\text { Number of } \\
\text { Participants }\end{array}$ & Participant Sex & $\begin{array}{c}\text { Mean age (range) } \\
\text { in years }\end{array}$ & $\begin{array}{l}\text { Diagnoses of } \\
\text { Participants }\end{array}$ & $\begin{array}{c}\text { Mean Duration of } \\
\text { Symptoms (range) in } \\
\text { Years }\end{array}$ \\
\hline Tsui (1993) [10] & Cross-over trial & 20 & $\begin{array}{c}7 \mathrm{~F} \\
13 \mathrm{M}\end{array}$ & $41(28-58)$ & $20 \mathrm{WC}$ & $5.2(2-14)$ \\
\hline Cole (1995) [11] & Cross-over trial & 10 & $\begin{array}{c}7 \mathrm{~F} \\
3 \mathrm{M}\end{array}$ & $49(36-66)$ & $\begin{array}{l}6 \mathrm{WC} \\
2 \mathrm{SC} \\
2 \mathrm{MC} \\
\end{array}$ & 8.5 \\
\hline \multirow{2}{*}{ Kruisdijk (2007) [12] } & \multirow{2}{*}{ Parallel-group trial } & $\begin{array}{c}\text { BTX-A } \\
\text { group: } 20\end{array}$ & $\begin{array}{c}10 \mathrm{~F} \\
10 \mathrm{M}\end{array}$ & $\begin{array}{c}\text { BTX-A } \\
\text { Group: } 48\end{array}$ & \multirow{2}{*}{$39 \mathrm{WC}$} & $\begin{array}{c}\text { BTX-A } \\
\text { Group: } 7.4\end{array}$ \\
\hline & & Placebo: 19 & $\begin{array}{c}7 \mathrm{~F} \\
12 \mathrm{M}\end{array}$ & Placebo: 46 & & Placebo: 9.1 \\
\hline
\end{tabular}

$\mathrm{WC}=$ writer's cramp; $\mathrm{SC}=$ stenographer's cramp; $\mathrm{MC}=$ musician's cramp; $\mathrm{F}=$ females; $\mathrm{M}=$ males

[4] Number of participants with any adverse events

[5] Number of participants with any serious adverse events

[6] Number of participants withdrawing due to adverse events

\subsection{Meta-Analysis}

For our meta-analysis, we computed a Relative Risk (RR) with a 95\% Confidence Interval (CI). Between study heterogeneity was assessed with the I-squared statistic and a random effects model was used for our meta-analysis because of the heterogeneity.

\section{RESULTS}

\subsection{Search Results}

Our searches yielded 1,116 publications from the databases searched with 674 publications remaining after deduplication. No additional references were identified from other sources. Applying the eligibility criteria to the titles and abstracts screened resulted in 24 articles left for full-text evaluation. Ultimately, three studies [10 - 12] met our inclusion criteria. Fig. (1) shows the PRISMA flow diagram. The publications excluded at the full-text stage and the reasons for exclusion are presented in Appendix B. As regards the included studies, two used a cross-over design and one used a parallel-group design. A total of 69 participants were involved in the three trials which included 31 women and 38 men. The evidence identified pertains to focal task-specific hand dystonias. Two of the studies were limited to participants who had been diagnosed with Writer's Cramp (WC), and overall the majority (94\%) of the participants had WC. The mean duration of symptoms in the participants was 7.5 years. Table $\mathbf{1}$ details the study designs and demographic characteristics of participants.

\subsection{Study Quality Assessment}

One study was given an Oxford Quality Scale score of 5/5 and two studies a score of $3 / 5$. Tsui et al. [10] was given an overall quality score of $3 / 5$ ( 1 point for randomization, 1 for blinding, 1 for description of dropouts). Similarly, Cole et al. [11] scored 3/5 (1 for randomization, 1 for blinding, and 1 for description of dropouts) and Kruisdijk et al. [12] achieved a maximum score of $5 / 5$.

\subsection{Efficacy}

Table 2 shows the muscles targeted, BTX dosages used, the outcome assessments employed, and the main results of the included studies. Identification of muscles to be injected was undertaken clinically in all the three trials and supplemented by Electromyographic (EMG) assessment in two $[10,11]$ of the three studies. The study authors used intramuscular injections of BTX-A or equal volumes of saline in all the trials. Doses of BTX-A varied between the participants depending on the selection and number of muscles. Generally, participants were assessed prior to the intervention, and at two weeks to onemonth post-intervention, or when any treatment effect had worn off.

The authors of the studies used a combination of selfreport by the participants and functional performance measurements. Different self-report questions were used. Tsui et al. [10] asked participants to report whether they noticed any changes in writing, which was scored as follows: $-1=$ worse; 0 = no change; 1 = improvement; and $2=$ dramatic improvement. Cole et al. [11] requested participants to complete a questionnaire about the amount of improvement of their muscles at the time of each assessment, using a categorical scale (major, moderate, minimal, or none), and a Visual Analog Scale (VAS). The VAS ranged from 0 (no improvement) to $10 \mathrm{~cm}$ (return to normal). Kruisdijk et al. [12] used the participants' answers to the following question as their primary outcome measure: "Considering all advantages and disadvantages of this treatment, is the improvement such that you wish to continue this treatment or not?" Functional performance measures included videotape analysis of writing samples, speed and accuracy of pen control, Gibson's maze assessment [13] (a spiral maze in which the participant is asked to trace the path in the maze from the center and work spirally outward with the pen as quickly as possible), Symptom Severity Scale (SSS) [14], Functional Status Scale (FSS) [14], and Writer's Cramp Rating Scale (WCRS) [15]. The specific scales used for functional performance assessments varied considerably between the three trials.

Tsui et al. [10] undertook a randomized controlled crossover trial of 20 participants with WC. They used three functional performance tests and the authors reported statistically significant improvement in the BTX-A treated participants in pen speed and accuracy, in three out of four 
Table 2. Intervention, assessment and main results of selected studies.

\begin{tabular}{|c|c|c|c|c|}
\hline $\begin{array}{c}\text { First Author } \\
\text { / Year }\end{array}$ & $\begin{array}{c}\text { Hand Muscles } \\
\text { Affected }\end{array}$ & $\begin{array}{l}\text { Intervention/Type of } \\
\text { Dose of BTX-A }\end{array}$ & $\begin{array}{c}\text { Type of Assessments/Outcome } \\
\text { Measures }\end{array}$ & Main Results \\
\hline $\begin{array}{c}\text { Tsui (1993) } \\
{[10]}\end{array}$ & \begin{tabular}{|} 
FDS, FCR, \\
FCU, FPL, \\
EDC, ECU, PT, \\
PQ
\end{tabular} & $\begin{array}{c}\text { BTX-A injection - } \\
\text { dose range } 25-50 \mathrm{MU}\end{array}$ & $\begin{array}{l}\text { 1. Self-report assessment of participant } \\
\text { writing on a four-point scale } \\
\text { 2. Speed and accuracy of pen control } \\
\text { 3. Gibson's maze } \\
\text { 4. Copying a standard passage } \\
\text { (readability scoring by "blind" } \\
\text { physician) }\end{array}$ & $\begin{array}{c}\text { Self-reported results were modest: } 4 / 20 \text { had } \\
\text { definite improvement, } 2 / 20 \text { had slight } \\
\text { improvement. } \\
\text { 8/12 participants described pain relief after } \\
\text { BTX-A. } \\
\text { For speed, significant mean change in } \\
\text { velocity from baseline to } 2 \text { weeks for BTX-A } \\
\text { was recorded for horizontal movement }(0.17 \\
\mathrm{cm} / \mathrm{sec}, \mathrm{p}<0.05) \text {; for vertical movement }(0.9 \\
\mathrm{cm} / \mathrm{sec}, \mathrm{p}<0.01) \text {; and for descending } \\
\text { movement }(0.39 \mathrm{~cm} / \mathrm{sec}, \mathrm{p}<0.05) \text {. } \\
\text { Mean time to complete Gibson's maze } \\
\text { significantly improved by } 3.23 \mathrm{sec}(\mathrm{p}<0.01) \\
\text { at } 2 \text { weeks, and by } 3.63 \mathrm{sec}(\mathrm{p}<0.01) \text { at } 6 \\
\text { weeks for participants on BTX-A. }\end{array}$ \\
\hline $\begin{array}{c}\text { Cole }(1995) \\
{[11]}\end{array}$ & $\begin{array}{c}\text { FCR, APL, } \\
\text { EPL, FDS, FPL, } \\
\text { FCU, FDP, } \\
\text { EDC }\end{array}$ & $\begin{array}{l}\text { BTX-A injection - } \\
\text { dose range 5-30 MU }\end{array}$ & \begin{tabular}{|} 
1. Self-report response about \\
improvement and weakness \\
2. Functional performance testing using: \\
a. MRC scales for muscle power \\
b. Timing of writing sample \\
c. Counting errors of writing "off-the- \\
line" for WC \\
d. Counting the number of errors for a \\
standard transcription for SC \\
e. MC participants played a standard \\
piece of music which was recorded on \\
videotape and assessed by five professors \\
of music
\end{tabular} & $\begin{array}{c}\text { 4/10 participants had major improvement, } \\
5 / 10 \text { had moderate improvement and } 1 / 10 \text { had } \\
\text { no improvement to BTX-A. } \\
\text { From MRC testing, } 7 / 10 \text { participants were } \\
\text { weaker with BTX-A, } 3 / 10 \text { had no difference } \\
\text { in strength after BTX-A, } 2 / 10 \text { had weakness } \\
\text { after placebo. } \\
\text { 4/6 participants with WC wrote faster after } \\
\text { BTX-A. } \\
\text { 2/2 participants with SC did not show any } \\
\text { improvement in BTX-A compared to placebo. } \\
\text { 2/2 participants with MC improved on BTX- } \\
\text { A compared to placebo. }\end{array}$ \\
\hline $\begin{array}{l}\text { Kruisdijk } \\
\text { (2007) [12] }\end{array}$ & FPL, FDP, EIP & $\begin{array}{c}\text { BTX-A injection - } \\
\text { 178 MU (range 30-240) } \\
\text { Placebo - volume equal to } \\
224 \text { MU (20-280) }\end{array}$ & $\begin{array}{l}\text { 1. Self-response to the question about } \\
\text { benefit of treatment } \\
\text { 2. Secondary outcome measures } \\
\text { included: } \\
\text { a. Visual analogue scale (VAS) for } \\
\text { handwriting } \\
\text { b. Symptom severity scale (SSS) } \\
\text { c. Functional status scale (FSS) } \\
\text { d. Writer's cramp rating scale (WCRS) } \\
\text { e. Writing speed }\end{array}$ & $\begin{array}{c}\text { Primary outcome }- \text { In the BTX-A group, } \\
14 / 20 \text { participants wished to continue } \\
\text { treatment versus } 6 / 19 \text { participants in the } \\
\text { placebo group. } \\
\text { Secondary outcome - The mean difference } \\
\text { comparing placebo to BTX-A from baseline } \\
\text { to } 8 \text { weeks of the objective measures were: } \\
\text { VAS: } 1.32 \mathrm{~cm}(95 \% \text { CI, } 0.33 \text { to } 2.3, \mathrm{p}=0.01) \\
\text { in favor of BTX-A. } \\
\text { SSS: }-2.44 \text { points }(95 \% \text { CI, }-4.52 \text { to }-0.37, \mathrm{p}= \\
0.02) \text { in favor of BTX-A. } \\
\text { FSS: } 2.07 \text { points }(95 \% \text { CI, }-0.4 \text { to } 4.54, p= \\
0.1) \text {. } \\
\text { WCRS: }-1.51 \text { points ( } 95 \% \text { CI, }-2.55 \text { to }-0.47 \text {, } \\
\text { p < } 0.01) \text { in favor of BTX-A. } \\
\text { Writing speed: } 1.14 \text { lines (95\% CI, } 0.07 \text { to } \\
2.20, p=0.04) \text { in favor of BTX-A. }\end{array}$ \\
\hline
\end{tabular}

FDS = Flexor Digitorum Superficialis; FCR = Flexor Carpi Radialis; FCU = Flexor Carpi Ulnaris; FPL = Flexor Pollicis Longus; EDC = Extensor Digitorum Communis; $\mathbf{E C U}=$ Extensor Carpi Ulnaris; PT $=$ Pronator Teres; $\mathbf{P Q}=$ Pronator Quadratus; $\mathbf{A P L}=$ Abductor Pollicis Longus; $\mathbf{E P L}=$ Extensor Pollicis Longus; $\mathbf{F D P}=$ Flexor Digitorum Profundus; EIP $=$ Extensor Indicis Propius.

MU $=$ Mouse Units; $\mathbf{M R C}=$ Medical Research Council

movement directions at two weeks, using a digitized pad. The study authors did not specify how the statistical analysis was performed and none of the placebo group results were reported in the paper. The authors did not respond to our email enquiry regarding this matter. Performance in the Gibson's maze task improved significantly in $9 / 20$ participants (45\%) for speed, and $7 / 20$ participants (35\%) for accuracy with BTX-A. Writing speed improved in $7 / 20$ participants $(35 \%)$ and the writing was more legible in $4 / 20$ participants $(20 \%)$, but no statistical testing was reported.

Of interest, participants who had abnormal wrist posture in association with their dystonia were reported to have a significantly stronger positive response to the BTX-A therapy.
Eleven out of 13 participants (85\%) with wrist-joint deviation improved on pen control versus $1 / 7$ participants (14\%) without deviation; 8/13 participants $(62 \%)$ with wrist deviation improved on Gibson's maze versus 1/7 participants (14\%) without deviation; and $7 / 13$ participants $(54 \%)$ versus $0 / 7$ improved on self-report with regards to writing. A chi-square analysis was reported comparing these two groups and the difference was found to be significant $(\mathrm{p}<0.001)$.

Eight out of 12 participants (67\%) with pain noted improvement in their symptoms following BTX-A injection but no statistical analysis was reported. The self-reported assessment of writing found $6 / 20$ participants (30\%) reporting improvement in writing, $13 / 20$ participants $(65 \%)$ with no 
change, and $1 / 20$ participants $(5 \%)$ transiently worse with BTX-A. The study authors reported that there were no changes in self-reported writing of participants during the placebo phase.

Cole et al. [11] performed a randomized cross-over trial of 10 participants comparing BTX-A with saline injections at two to four weeks post-injection. These were highly selected participants in that they came from the study authors' existing clinic population and were patients "who stated that they had a definite subjective response to open-label treatment with BTXA", and, furthermore, whose dose of BTX-A had been optimized already. This study, therefore, is a complete enriched enrolment trial [16]. The washout period varied from two weeks to four months depending on whether the "patient and physician determined that the [prior] injection might have had some effect". None of the results from any of the outcomes of the trial (either subjective feeling of 'improvement' by the patient or the objective measures of changes in muscle strength, writing speed, transcription speed, physician rating of motor performance of all participants and rating of musical performances by professors of music who were blinded to the treatment groups) were subjected to statistical analysis and the results were therefore purely descriptive. Manual muscle testing using the Medical Research Council (MRC) scale [17] found that $7 / 10$ participants $(70 \%)$ were weaker when injected with BTX-A compared to placebo and 2/10 participants (20\%) were weaker with placebo than with BTX-A. For participants with $\mathrm{WC}$, the time required to write a standard paragraph was recorded, and errors of writing "off-the-line" were counted and used for objective assessment. Four out of six participants $(67 \%)$ with WC wrote faster after BTX-A, and 2/3 participants (67\%) who wrote "off the line" improved after BTX-A injection. One participant who was only able to print after placebo could write a standard paragraph in longhand after BTX-A. Two stenographers did not reduce their transcription error rate after BTX-A. Two musicians judged by a panel of professors of music were thought to give better performances after BTX-A injections. The study authors found that $9 / 10$ participants (" $90 \%$ " stated in results table but the study authors reported " $80 \%$ " in the article text) improved in self-rated assessments with $4 / 10$ participants (40\%) rating the improvement as major two weeks after BTX-A injections. With placebo, 4/10 participants (40\%) still responded positively, with $1 / 10$ participant $(10 \%)$ noting major improvement. Generally, the authors of this study indicated that $5 / 10$ participants $(50 \%)$ performed better after BTX-A injections during functional performance testing. One participant was weaker, wrote faster and performed better with placebo injection. Overall 8/10 BTX-A participants (80\%) reported improvement and $4 / 10$ participants (40\%) receiving placebo injections reported benefit.

Kruisdijk et al. [12] compared BTX-A treated WC participants to placebo. Some of the participants involved in this trial also had electrophysiological measurements that Contarino et al. [18] reported elsewhere. The primary outcome measure for this study was the participants' answers to the following question: "Considering all advantages and disadvantages of this treatment, is the improvement such that you wish to continue this treatment or not?" The study authors found that $14 / 20$ participants $(70 \%)$ in the BTX-A group wished to continue treatment versus $6 / 19$ participants $(32 \%)$ in the placebo group $(\mathrm{p}=0.03)$. The study authors used an unpaired t-test to analyze the mean difference for functional performance measures which was calculated by subtracting the change in baseline to eight weeks with placebo from the change in baseline to eight weeks with BTX-A treatment. They reported a significant mean difference which was better with BTX-A regarding SSS, WCRS, writing speed (lines) and VAS for handwriting. The mean difference in the FSS was not significant. A subgroup analysis showed no evidence of treatment difference between the subgroups of participants with simple versus complex WC. The study authors reported that 20/39 participants $(51 \%)$ received treatment for a year after completion of the study because of its benefit.

Writing speed was used in all three trials for assessing the participants. In Tsui et al. [10] the time is taken to complete copying a standard passage and the number of words per minute was apparently recorded but was not presented in that publication. They noted that writing speed improved in $7 / 20$ participants (35\%). The writing samples from the participants were randomized and given to a "blinded" physician for scoring on a scale of 0 to $3(0=$ totally illegible; $1=$ some words illegible; 2 = all words legible, some with difficulty; and $3=$ all words easily legible). In the study by Cole et al. [11] participants with WC wrote a standard paragraph, and the time required for its completion was recorded. The study authors reported that $4 / 6$ participants $(67 \%)$ with WC wrote faster after the BTX-A injections. Though individual writing speeds of the participants were provided, a summary statistical analysis was not presented in the paper. Kruisdijk et al. [12] conducted a test of writing speed by measuring the number of lines of a standard text written within two minutes. The mean difference in the writing speed between placebo and BTX-A from baseline to 8 weeks was 1.14 lines $(95 \%$ CI, 0.07 to 2.20 , $\mathrm{p}=0.04$ ), better with BTX-A.

Two studies $[11,12]$ were included in our meta-analysis (Tsui et al. [10] did not report results in the placebo group and therefore could not be included in the meta-analysis). Combining the results of the self-rated improvements in these studies showed that the pooled effect estimate was not significantly different from placebo $(p=0.07)$ Fig. (2).

\subsection{Safety}

Muscle weakness after BTX-A injections was noted in participants in all three trials. In the trial by Tsui et al. [10], all 20 participants who had BTX-A experienced muscle weakness. Seven out of 10 participants (70\%) in the trial by Cole et al. [11] had muscle weakness. Kruisdijk et al. [12] reported weakness in the hand in 18/20 participants (90\%) in the BTXA group and in $2 / 19$ participants (11\%) in the placebo group. In the study by Kruisdijk et al. [12] the authors reported that $1 / 20$ participants (5\%) in the BTX-A group and 3/19 participants $(16 \%)$ in the placebo group reported pain at the injection site. Overall, 46/50 participants (92\%) experienced weakness of the muscles injected, which appeared to be transient with spontaneous recovery. One participant, however, experienced weakness which lasted for eight days. Across the studies, 49 participants received placebo but results were only reported on 


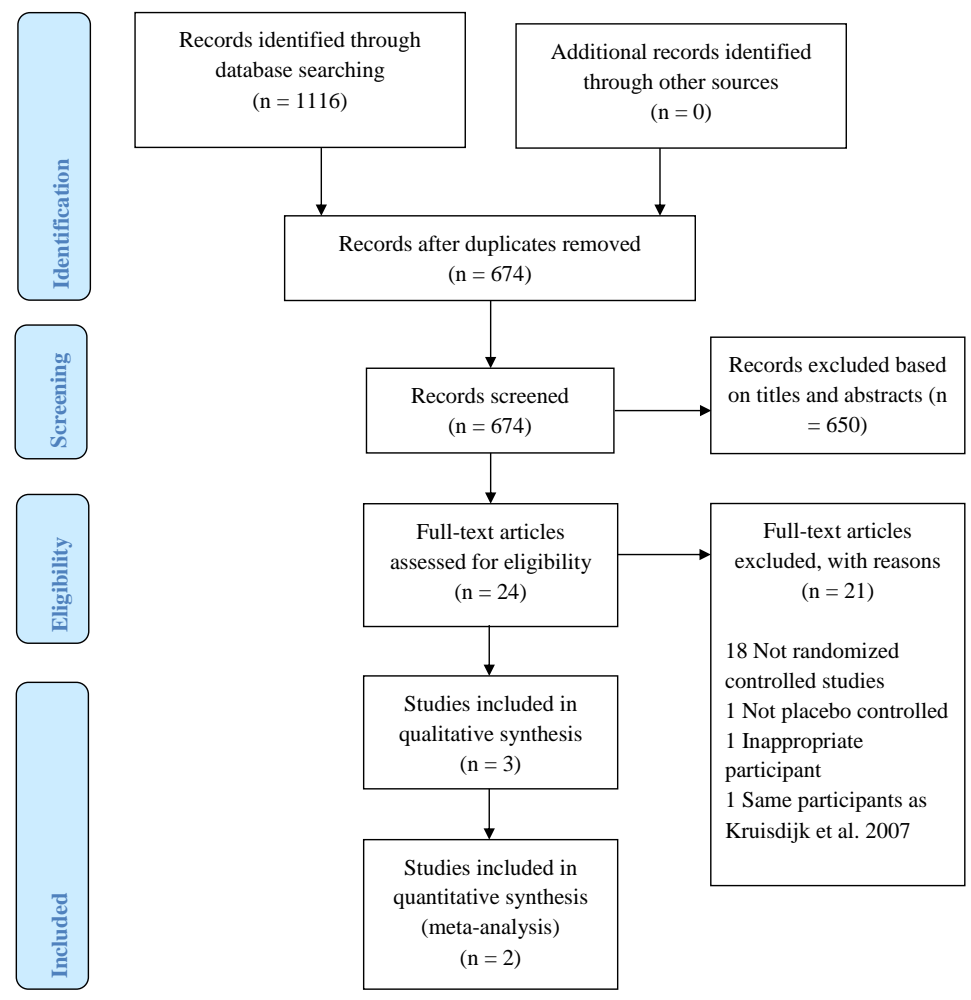

Fig. (1). Study Selection [6].

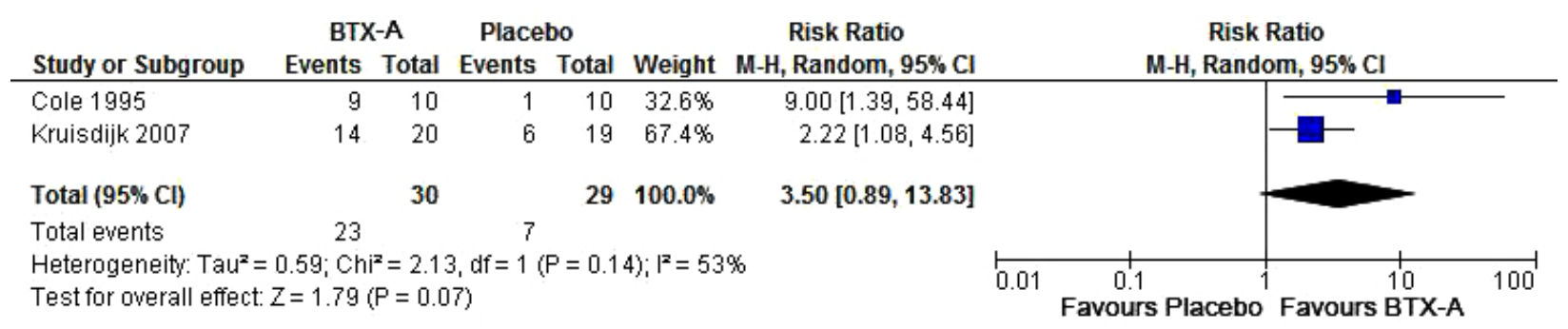

Fig. (2). Effect of BTX-A on hand function. The effect of BTX-A on hand function when compared to placebo was investigated using a random effects model. Tsui et al. (1993) did not report results in the placebo group and therefore these data could not be included in this meta-analysis. The events shown here represent self-reported benefit of BTX-A on hand function. BTX-A = Botulinum Toxin Subtype A; CI = Confidence Interval; M-H $=$ Mantel-Haenszel test; $\mathrm{df}=$ degrees of freedom.

Table 3. Adverse Events.

\begin{tabular}{|l|c|c|c|}
\hline First Author / Year & Participants with any Adverse Event & $\begin{array}{c}\text { Participants with any Serious } \\
\text { Adverse Event }\end{array}$ & $\begin{array}{c}\text { Participants withdrawing due to } \\
\text { Adverse Events }\end{array}$ \\
\hline Tsui (1993) [10] & $\begin{array}{c}20 / 20 \text { participants had weakness after BTX-A injection. } \\
12 / 20 \text { had pain at site of injection. }\end{array}$ & None reported & None reported \\
\hline Cole (1995) [11] & $\begin{array}{c}7 / 10 \text { participants had muscle weakness with BTX-A. } \\
2 / 10 \text { had weakness with placebo. }\end{array}$ & None reported & None reported \\
\hline Kruisdijk (2007) [12] & $\begin{array}{c}18 / 20 \text { participants had weakness in the hand with BTX- } \\
\text { A. } \\
\text { 2/19 participants reported hand weakness with placebo. }\end{array}$ & None reported \\
\hline
\end{tabular}

29 participants. Four of these 29 participants who received a placebo (14\%) developed weakness. The study authors reported that the weakness and pain were temporary and participants recovered completely. Tsui et al. [10] noted that besides weakness in the participants who received BTX-A, no other adverse events or systemic adverse reactions were reported. Those participants who received placebo reported no adverse events. Cole et al. [11] also reported that BTX-A was 
generally "safe to use". Kruisdijk et al. [12] reported that only $1 / 20$ participants $(5 \%)$ on BTX-A and 3/19 participants (16\%) on placebo had pain at the injection site. No serious adverse events were reported in any of the studies. None of the participants in any of the three studies was reported to have withdrawn from the trials.

\section{DISCUSSION}

This systematic review identified only three [10 - 12] published articles that evaluated BTX for FHD in randomized, double-blind, placebo-controlled trials.

\subsection{Validated Measures of Improvement in Hand Function}

Our primary outcome of interest in this systematic review was hand function, as measured by any validated hand function assessment at two weeks to two months post-treatment with BTX or placebo. In all three trials [10 - 12] the participants were evaluated within this primary time frame. Validated measures of hand function were used in two $[10,12]$ of the three trials. Tsui et al. [10] used Gibson's maze as a validated measure of improvement in hand function. They noted that the errors made and the time to complete the maze improved from the baseline to two weeks and then at six weeks following BTX-A treatment. This improvement was found to be significant $(\mathrm{p}<0.01)$. No participant improved on placebo treatment with Gibson's maze assessment. Kruisdijk et al. [12] used the WCRS, also a validated measure, scored on a scale from 0 to 16 points, to compare BTX-A treatment and placebo from baseline to eight weeks of treatment; they reported significant improvement in the WCRS, with a mean difference of -1.51 points $(95 \% \mathrm{CI},-2.55$ to $-0.47, \mathrm{p}<0.01)$ in favor of BTX-A. The FSS and the SSS have been validated for use in carpal tunnel syndrome, but to our knowledge, neither these tools nor the VAS have been validated specifically for FHD. Cole et al. [11] used other dystonia inducing tasks and measured the improvement in hand function, but as far as we know, these measures have also not been validated. None of the publications reported on validated measures of hand function at two months to six months post-treatment.

\subsection{Reduction in Symptoms}

Another secondary outcome, reduction in symptoms associated with FHD, was investigated as part of this systematic review. Tremor and myoclonus were not described as characteristics of FHD in any participant pre-treatment. It should be noted that a reduction in pain may have been represented in the participant's subjective assessments, but this was only explicitly described by Tsui et al. [10] and Kruisdijk et al. [12] Tsui et al. [10] found that 8/12 participants (67\%) with pain improved with BTX-A and none with placebo on subjective assessment. Kruisdijk et al. [12] used the SSS to evaluate the direct and indirect symptoms of WC (pain, spasm, weakness, and numbness). Though they did not elaborate on each of these symptoms, the study authors demonstrated a statistically significant improvement in overall symptoms with a mean difference, -2.44 points, $(95 \% \mathrm{CI},-4.52$ to $-0.37, \mathrm{p}=$ 0.02 ) favoring BTX-A over placebo from baseline to eight weeks.

\subsection{Quality of Life Measures}

No specific quality of life measures were reported in any of the three trials.

\subsection{Adverse Events}

The intended therapeutic effect of BTX is to create weakness in the antagonist muscles but only to the extent that the dystonic symptoms are reduced. Weakness to the extent that it limits desired hand functions would be considered an adverse event. The three studies [10 - 12] had a total of 50 participants who received BTX-A injections. Overall, 46/50 participants $(92 \%)$ experienced weakness of the muscles injected, which appeared to be transient with spontaneous recovery. Four out of 29 participants (14\%) who received placebo developed weakness. Kruisdijk et al. [12] reported that only $1 / 20$ participants $(5 \%)$ on BTX-A and $3 / 19$ participants $(16 \%)$ who received placebo had pain at the injection site.

\subsection{Limitations}

The number of participants in all three studies was small, severely limiting any conclusions that can be drawn from our analysis. Only one study, Cole et al. [11] involved musicians and stenographers, a total of four such participants. This review is therefore essentially about WC. A major problem with research on BTX is that the nature of the treatment and the predictability of the weakness may make it impossible to adequately blind participants (and there are also challenges in blinding assessors).

\subsection{Authors' Conclusions}

The number of participants included in this systematic review is too small to draw dependable conclusions for clinical practice about the efficacy and safety of BTX-A for FHD. There is currently not enough evidence to recommend the routine use of BTX-A for FHD, even though the treatment does show some promise. We would like to emphasize that this conclusion is reached because of a lack of dependable evidence for effectiveness derived from clinical trials, not because of evidence for lack of effectiveness of the intervention. As such, future studies are needed and our conclusions may need to be revisited when further quality evidence on sufficient numbers of patients is available.

\subsection{Future Research Direction}

There is a need for more and larger studies to evaluate BTX in FHD. In order to detect effect sizes ranging from 0.55 to 0.94 of having favorable outcomes between the intervention group receiving BTX and placebo or alternative treatment (as reported in Kruisdijk et al. [12]) a range of 19 to 53 participants per group needs to be recruited to attain a power of $80 \%$ with a type I error of 0.05 .

The effectiveness of blinding participants and assessors could also be explored in future research on FHD. For example, future trials may report on the proportion of patients correctly guessing their treatment group allocation. Trials could be of either parallel group design or crossover design, and it would be informative to investigate if blinding is more effectively maintained in parallel group trials, where the study participants only encounter either the active intervention or placebo in the context of the study.

Also, adhering to a core set of outcomes as regards measures of both efficacy and safety is recommended, because it would aid the comparability of future studies and would also enable us to combine such studies in future meta-analyses. Specifically, we would recommend adhering to the efficacy outcomes detailed in this review, namely: hand function as 
measured by a validated tool at two weeks to two months posttreatment, a validated assessment of hand function at two to six months post-treatment, the secondary symptoms pain and tremor, and an assessment of quality of life using a validated tool. As regards safety outcomes, we recommend reporting on the numbers of participants experiencing any adverse event, any serious adverse event, or withdrawing due to an adverse event.

Future research should furthermore specifically address distinct occupational groups, such as musicians and stenographers, and stratify the results for the different task specific dystonias.

\section{CONSENT FOR PUBLICATION}

Not applicable.

\section{CONFLICT OF INTEREST}

The authors declare no conflict of interest, financial or otherwise.

\section{ACKNOWLEDGEMENTS}

The authors are grateful to Dr. Tanya Jackson for editorial comments on the manuscripts.

\section{DISCLOSURE STATEMENTS}

This study was supported by a grant from the Workers' Compensation Board of Alberta.

Dr. Nigel Ashworth reports no disclosures.

Dr. Henry Aidoo reports no disclosures.

Dr. David Antle reports no disclosures.

Dr. Alexander Doroshenko reports no disclosures.

Dr. Charl Els reports no disclosures.

Dr. David M. Flaschner reports no disclosures.

Dr. Douglas P. Gross reports no disclosures.

Dr. Christine Guptill reports no disclosures.

Dr. Patrick Potter reports no disclosures.

Ms. Maria C. Tan reports no disclosures.

Dr. Sebastian Straube has received funding for a program of research of which the present systematic review is part, from the Workers' Compensation Board of Alberta. Dr. Straube also declares honoraria from the Workers' Compensation Board of Alberta and from Oxford Medical Knowledge as well as advisory board fees from Daiichi Sankyo, Inc.

\section{Appendix A: Search Strategies}

Ovid MEDLINE(R) Epub Ahead of Print, In-Process \& Other Non-Indexed Citations, Ovid MEDLINE(R) Daily and Ovid MEDLINE(R) 1946 to Present

\begin{tabular}{|c|c|c|}
\hline \# & Searches & Results \\
\hline 1 & Dystonic disorders/ or (dystoni* or cramp*).mp. & 24899 \\
\hline 2 & \begin{tabular}{|l} 
upper extremity/ or exp hand/ or (hand* or finger* or wrist* or phalanx or phalanges or digit or digits or digital or thumb* or palm* or \\
digitorum or carpi or carpal* or metacarpal* or pollicis or interphalangeal or stenographer* or writer* or typist* or telegraphist* or \\
musician* or clarinet* or flautist* or flutist* or flute or oboe or oboist* or saxophone or saxophonist* or bagpipe* or bassoon or \\
bassoonist* or guitar or guitarist* or bass or bassist* or banjo* or harp or harpist* or zither* or mandolin* or koto* or string player* or \\
violin or violinist* or viola or violist* or cello or cellist* or keyboard* or pianist* or piano* or organist* or harpsichord* or accordion* \\
or percussion* or drummer* or tabla* or bata or brass or trumpet* or trombon* or tuba or hornplayer* or barber* or beautician* or \\
golfer*).mp.
\end{tabular} & 1016570 \\
\hline 3 & 1 and 2 & 2520 \\
\hline 4 & ((focal and dystoni* and (limb* or extremit*)) or yips).ti,ab,kf. & 310 \\
\hline 5 & 3 or 4 & 2707 \\
\hline 6 & $\begin{array}{c}\text { exp Botulinum toxins/ or exp Clostridium botulinum/ or (Botox or BTX or botulin* or Meditoxin or Neuronox or Oculinum or } \\
\text { OnabotulinumtoxinA or Abobotulinumtoxina or Evabotulinumtoxina or Incobotulinumtoxina or Allergan or Azzalure or Bocouture or } \\
\text { Botox or Dysport or Onaclostox or Toxine botulinique or Vistabel or Xeomin or rimabotulinum* or Myobloc or NeuroBloc or } \\
\text { Bontoxilysin or Tentoxilysin or "Tetanus neurotoxin").mp. }\end{array}$ & 23013 \\
\hline 7 & 5 and 6 & 372 \\
\hline 8 & randomized controlled trial.pt. & 482732 \\
\hline 9 & clinical trial.pt. & 534532 \\
\hline 10 & randomi?ed.ti,ab. & 541005 \\
\hline 11 & placebo.ti,ab. & 202113 \\
\hline 12 & dt.fs. & 2066830 \\
\hline 13 & randomly.ti,ab. & 293378 \\
\hline 14 & trial.ti,ab. & 520363 \\
\hline 15 & groups.ti,ab. & 1829727 \\
\hline 16 & or/8-15 & 4443267 \\
\hline 17 & animals/ & 6372284 \\
\hline 18 & humans/ & 17419632 \\
\hline 19 & 17 not (17 and 18$)$ & 4556224 \\
\hline 20 & 16 not 19 & 3858878 \\
\hline \begin{tabular}{l|l}
21 & \\
\end{tabular} & 7 and 20 & 244 \\
\hline
\end{tabular}


(Appendix A) contd....

\begin{tabular}{|c|c|c|}
\hline$\#$ & Searches & Results \\
\hline 22 & remove duplicates from 21 & 236 \\
\hline
\end{tabular}

\section{Embase}

1974 to 2017 September 28

Interface - OVID

\begin{tabular}{|c|c|c|}
\hline \# & Searches & Results \\
\hline 1 & dystonia/ or dystonic disorder/ or (dystoni* or cramp*).ti,ab,kf. & 38576 \\
\hline 2 & $\begin{array}{l}\text { upper extremity/ or exp hand/ or (hand* or finger* or wrist* or phalanx or phalanges or digit or digits or digital or thumb* or palm* or } \\
\text { digitorum or carpi or carpal* or metacarpal* or pollicis or interphalangeal or stenographer* or writer* or typist* or telegraphist* or } \\
\text { musician* or clarinet* or flautist* or flutist* or flute or oboe or oboist* or saxophone or saxophonist* or bagpipe* or bassoon or } \\
\text { bassoonist* or guitar or guitarist* or bass or bassist* or banjo* or harp or harpist* or zither* or mandolin* or koto* or string player* or } \\
\text { violin or violinist* or viola or violist* or cello or cellist* or keyboard* or pianist* or piano* or organist* or harpsichord* or accordion* } \\
\text { or percussion* or drummer* or tabla* or bata or brass or trumpet* or trombon* or tuba or hornplayer* or barber* or beautician* or } \\
\text { golfer*).ti,ab,kf. }\end{array}$ & 1097218 \\
\hline 3 & 1 and 2 & 4142 \\
\hline 4 & exp focal hand dystonia/ or ((focal and dystoni* and (limb* or extremit*)) or yips).ti,ab,kf. & 1248 \\
\hline 5 & 3 or 4 & 4584 \\
\hline 6 & $\begin{array}{c}\text { exp Botulinum toxins/ or exp Clostridium botulinum/ or (Botox or BTX or botulin* or Meditoxin or Neuronox or Oculinum or } \\
\text { OnabotulinumtoxinA or Abobotulinumtoxina or Evabotulinumtoxina or Incobotulinumtoxina or Allergan or Azzalure or Bocouture or } \\
\text { Botox or Dysport or Onaclostox or Toxine botulinique or Vistabel or Xeomin or rimabotulinum* or Myobloc or NeuroBloc or } \\
\text { Bontoxilysin or Tentoxilysin or "Tetanus neurotoxin").ti,ab,kf. }\end{array}$ & 33291 \\
\hline 7 & 5 and 6 & 785 \\
\hline 8 & exp clinical trial/ & 1262347 \\
\hline 9 & randomi?ed.ti,ab. & 711891 \\
\hline 10 & placebo.ti,ab. & 261316 \\
\hline 11 & dt.fs. & 3484972 \\
\hline 12 & randomly.ti,ab. & 365388 \\
\hline 13 & trial.ti,ab. & 677385 \\
\hline 14 & groups.ti,ab. & 2374964 \\
\hline 15 & or/8-14 & 6529004 \\
\hline 16 & animal/ & 1812089 \\
\hline 17 & human/ & 18870014 \\
\hline 18 & 16 not (16 and 17$)$ & 1379198 \\
\hline 19 & 15 not 18 & 6364607 \\
\hline 20 & 7 and 19 & 505 \\
\hline 21 & remove duplicates from 20 & 495 \\
\hline
\end{tabular}

\section{CINAHL Plus with Full Text}

Interface - EBSCOhost Research Databases

Search Screen - Advanced Search

\begin{tabular}{|c|c|c|}
\hline$\#$ & Query & Results \\
\hline S1 & (MH "Dystonic disorders") OR (MH "Dystonia") OR (dystoni* or cramp*) & 4,475 \\
\hline S2 & $\begin{array}{c}\text { (MH "Upper extremity") OR (MH "Hand+") OR (hand* or finger* or wrist* or phalanx or phalanges or digit or digits or digital or } \\
\text { thumb* or palm* or digitorum or carpi or carpal* or metacarpal* or pollicis or interphalangeal or stenographer* or writer* or typist* } \\
\text { or telegraphist* or musician* or clarinet* or flautist* or flutist* or flute or oboe or oboist* or saxophone or saxophonist* or bagpipe* } \\
\text { or bassoon or bassoonist* or guitar or guitarist* or bass or bassist* or banjo* or harp or harpist* or zither* or mandolin* or koto* or } \\
\text { string player* or violin or violinist* or viola or violist* or cello or cellist* or keyboard* or pianist* or piano* or organist* or } \\
\text { harpsichord* or accordion* or percussion* or drummer* or tabla* or bata or brass or trumpet* or trombon* or tuba or hornplayer* or } \\
\text { barber* or beautician* or golfer*) }\end{array}$ \\
\hline
\end{tabular}




\begin{tabular}{|c|c|c|}
\hline$\#$ & Query & Results \\
\hline $\mathrm{S} 3$ & S1 AND S2 & 496 \\
\hline $\mathrm{S} 4$ & (MH "Focal hand dystonia") OR ((focal and dystoni* and (limb* or extremit*)) or yips) & 168 \\
\hline S5 & S3 OR S4 & 561 \\
\hline S6 & $\begin{array}{c}\text { (MH "Botulinum toxins") OR (Botox or BTX or botulin* or Meditoxin or Neuronox or Oculinum or OnabotulinumtoxinA or } \\
\text { Abobotulinumtoxina or Evabotulinumtoxina or Incobotulinumtoxina or Allergan or Azzalure or Bocouture or Botox or Dysport or } \\
\text { Onaclostox or "Toxine botulinique" or Vistabel or Xeomin or rimabotulinum* or Myobloc or NeuroBloc or Bontoxilysin or } \\
\text { Tentoxilysin or "Tetanus neurotoxin") }\end{array}$ & 5,028 \\
\hline S7 & S5 AND S6 & 82 \\
\hline S8 &  & $2,107,928$ \\
\hline S9 & S7 AND S8 & 46 \\
\hline
\end{tabular}

\section{SPORT Discus with Full Text.}

Interface - EBSCOhost Research Databases

Search Screen - Advanced Search

\begin{tabular}{|c|c|c|}
\hline$\#$ & Query & Results \\
\hline S1 & DE “DYSTONIA" OR DE "FOCAL dystonia” OR (dystoni* or cramp*) & 1,660 \\
\hline $\mathrm{S} 2$ & $\begin{array}{l}\text { DE "ARM" OR (DE "WRIST" OR DE “CARPAL bones" OR DE "WRIST extension" OR DE "WRIST flexion") OR (DE "HAND" } \\
\text { OR DE "FINGERS" OR DE "FLEXOR tendons" OR DE "METACARPUS") OR (hand* or finger* or wrist* or phalanx or phalanges } \\
\text { or digit or digits or digital or thumb* or palm* or digitorum or carpi or carpal* or metacarpal* or pollicis or interphalangeal or } \\
\text { stenographer* or writer* or typist* or telegraphist* or musician* or clarinet* or flautist* or flutist* or flute or oboe or oboist* or } \\
\text { saxophone or saxophonist* or bagpipe* or bassoon or bassoonist* or guitar or guitarist* or bass or bassist* or banjo* or harp or harpist* } \\
\text { or zither* or mandolin* or koto* or string player* or violin or violinist* or viola or violist* or cello or cellist* or keyboard* or pianist* } \\
\text { or piano* or organist* or harpsichord* or accordion* or percussion* or drummer* or tabla* or bata or brass or trumpet* or trombon* or } \\
\text { tuba or hornplayer* or barber* or beautician* or golfer*) }\end{array}$ & 160,253 \\
\hline S3 & S1 AND S2 & 160 \\
\hline S4 & (focal and dystoni* and (limb* or extremit*)) or yips & 256 \\
\hline S5 & S3 OR S4 & 388 \\
\hline S6 & $\begin{array}{c}\text { DE "BOTULINUM toxin" OR (Botox or BTX or botulin* or Meditoxin or Neuronox or Oculinum or OnabotulinumtoxinA or } \\
\text { Abobotulinumtoxina or Evabotulinumtoxina or Incobotulinumtoxina or Allergan or Azzalure or Bocouture or Botox or Dysport or } \\
\text { Onaclostox or "Toxine botulinique" or Vistabel or Xeomin or rimabotulinum* or Myobloc or NeuroBloc or Bontoxilysin or } \\
\text { Tentoxilysin or "Tetanus neurotoxin") }\end{array}$ & 930 \\
\hline S7 & S5 AND S6 & 13 \\
\hline
\end{tabular}

\section{Cochrane Library}

Interface - Wiley Interscience

Strategy applied to CDSR, DARE, CENTRAL

\begin{tabular}{|c|c|c|}
\hline ID & Search & Hits \\
\hline$\# 1$ & [mh ${ }^{\wedge}$ 'Dystonic disorders"] or (dystoni* or cramp*):ti,ab,kw & 2607 \\
\hline$\# 2$ & $\begin{array}{l}\text { [mh }{ }^{\wedge} \text { "Upper extremity”] or [mh hand] or (hand* or finger* or wrist* or phalanx or phalanges or digit or digits or digital or thumb* or } \\
\text { palm* or digitorum or carpi or carpal* or metacarpal* or pollicis or interphalangeal or stenographer* or writer* or typist* or telegraphist* } \\
\text { or musician* or clarinet* or flautist* or flutist* or flute or oboe or oboist* or saxophone or saxophonist* or bagpipe* or bassoon or } \\
\text { bassoonist* or guitar or guitarist* or bass or bassist* or banjo* or harp or harpist* or zither* or mandolin* or koto* or string player* or } \\
\text { violin or violinist* or viola or violist* or cello or cellist* or keyboard* or pianist* or piano* or organist* or harpsichord* or accordion* or } \\
\text { percussion* or drummer* or tabla* or bata or brass or trumpet* or trombon* or tuba or hornplayer* or barber* or beautician* or } \\
\text { golfer*):ti,ab,kw }\end{array}$ & 45535 \\
\hline
\end{tabular}


(Appendix A) contd.....

\begin{tabular}{|c|c|c|}
\hline ID & Search & Hits \\
\hline$\# 3$ & $\# 1$ and $\# 2$ & 180 \\
\hline$\# 4$ & ((focal and dystoni* and (limb* or extremit*)) or yips):ti,ab,kw & 11 \\
\hline$\# 5$ & $\# 3$ or \#4 & 190 \\
\hline$\# 6$ & $\begin{array}{c}\text { [mh "Botulinum toxins"] or [mh "Clostridium botulinum"] or (Botox or BTX or botulin* or Meditoxin or Neuronox or Oculinum or } \\
\text { OnabotulinumtoxinA or Abobotulinumtoxina or Evabotulinumtoxina or Incobotulinumtoxina or Allergan or Azzalure or Bocouture or } \\
\text { Botox or Dysport or Onaclostox or Toxine botulinique or Vistabel or Xeomin or rimabotulinum* or Myobloc or NeuroBloc or } \\
\text { Bontoxilysin or Tentoxilysin or "Tetanus neurotoxin"):ti,ab,kw }\end{array}$ & 2800 \\
\hline$\# 7$ & $\# 5$ and $\# 6$ & 34 \\
\hline
\end{tabular}

\section{Scopus}

((TITLE-ABS-KEY (botox OR btx OR botulin* OR meditoxin OR neuronox OR oculinum OR onabotulinumtoxina OR abobotulinumtoxina OR evabotu-linumtoxina OR incobotulinumtoxina OR allergan OR azzalure OR bocouture OR botox OR dysport OR onaclostox) OR TITLE-ABS-KEY ("Toxine botulinique" OR vistabel OR xeomin OR rimabotulinum* OR myobloc OR neurobloc OR bontoxilysin OR tentoxilysin OR “Tetanus neurotoxin"))) AND ((TITLEABS-KEY ((dys-toni* OR cramp*) W/3 (hand* OR finger* OR wrist* OR phalanx OR phalanges OR digit OR digits OR digital OR thumb* OR palm* OR digitorum OR carpi OR carpal* OR metacarpal* OR pollicis OR interphalangeal))) OR (TITLE-ABS-KEY ((dystoni* OR cramp*) W/3 (stenographer* OR writer* OR typist* OR telegraphist*))) OR (TITLE-ABS-KEY ((dystoni* OR cramp*) W/3 (musician* OR clarinet* OR flautist* OR flutist* OR flute OR oboe OR oboist* OR saxophone OR saxophonist* OR bagpipe* OR bassoon OR bassoonist* OR guitar OR guitarist* OR bass OR bassist* OR banjo* OR harp OR harpist*))) OR (TITLE-ABSKEY ((dystoni* OR cramp*) W/3 (zither* OR mandolin* OR koto* OR "string player*" OR violin OR violinist* OR viola

\section{Web of Science Core Collection}

Timespan $=$ All years
OR violist* OR cello OR cellist*))) OR ( TITLE-ABS-KEY ((dystoni* OR cramp*) W/3 (keyboard* OR pianist* OR piano* OR organist* OR harpsichord* OR accordion* OR percussion* OR drum-mer* OR tabla* OR bata))) OR (TITLEABS-KEY (( dystoni* OR cramp*) W/3 (brass OR trumpet* OR trombon* OR tuba OR hornplayer* OR barber* OR beautician* OR golfer*))) OR (TITLE-ABS-KEY ("golf* Yips”))) AND ((TITLE-ABS-KEY (clinical W/2 research) OR TITLE-ABS-KEY (random* OR cross?over OR placebo* OR control* OR factorial OR sham* OR meta?analy* OR systematic AND review* OR blind* OR mask* OR trial*)))

\section{PEDro}
Setting: Basic Search
5 separate searches:
dystoni* AND hand*
dystoni* AND wrist*
dystoni* AND finger*
dystoni* AND musician*
cramp* AND musician*

\begin{tabular}{|c|c|c|}
\hline Set & Results & Search \\
\hline$\# 5$ & 191 & $\begin{array}{c}\text { \#4 AND \#3 } \\
\text { DocType }=\text { All document types; Language }=\text { All languages; }\end{array}$ \\
\hline$\# 4$ & $7,212,290$ & $\begin{array}{c}\text { TOPIC: (clinical NEAR/2 research) ORTOPIC: }(\text { random* OR cross?over OR placebo* OR control* OR factorial OR sham* OR } \\
\text { meta?analy* OR systematic AND review* OR blind* OR mask* OR trial*) } \\
\text { DocType }=\text { All document types; Language }=\text { All languages; }\end{array}$ \\
\hline$\# 3$ & 379 & $\begin{array}{c}\# 2 \text { AND } \# 1 \\
\text { DocType }=\text { All document types; Language }=\text { All languages; }\end{array}$ \\
\hline$\# 2$ & 26,825 & $\begin{array}{l}\text { TOPIC: (Botox or BTX or botulin* or Meditoxin or Neuronox or Oculinum or OnabotulinumtoxinA or Abobotulinumtoxina or } \\
\text { Evabotulinumtoxina or Incobotulinumtoxina or Allergan or Azzalure or Bocouture or Botox or Dysport or Onaclostox Or "Toxine } \\
\text { botulinique" or Vistabel or Xeomin or rimabotulinum* or Myobloc or NeuroBloc or Bontoxilysin or Tentoxilysin or "Tetanus } \\
\text { neurotoxin") } \\
\text { DocType=All document types; Language=All languages; }\end{array}$ \\
\hline \begin{tabular}{|l|}
$\# 1$ \\
\end{tabular} & 1,932 & $\begin{array}{l}\text { TOPIC: ((dystoni* or cramp*) NEAR/3 (hand* or finger* or wrist* or phalanx or phalanges or digit or digits or digital or thumb* or } \\
\text { palm* or digitorum or carpi or carpal* or metacarpal* or pollicis or interphalangeal)) OR TOPIC: ((dystoni* or cramp*) NEAR/3 } \\
\text { (stenographer* or writer* or typist* or telegraphist* or musician* or clarinet* or flautist* or flutist* or flute or oboe or oboist* or } \\
\text { saxophone or saxophonist* or bagpipe* or bassoon or bassoonist* or guitar or guitarist* or bass or bassist* or banjo* or harp or } \\
\text { harpist* or zither* or mandolin* or koto* or "string player*" or violin or violinist* or viola or violist* or cello or cellist* or } \\
\text { keyboard* or pianist* or piano* or organist* or harpsichord* or accordion* or percussion* or drummer* or tabla* or bata or brass or } \\
\text { trumpet* or trombon* or tuba or hornplayer* or barber* or beautician* or golfer*)) OR TOPIC: ("golf* Yips") } \\
\text { DocType=All document types; Language=All languages; }\end{array}$ \\
\hline
\end{tabular}




\section{Clinicaltrials.gov}

Setting - Advanced Search

Condition/Disease:

"Focal hand dystonia" OR (focal AND dystonia AND (wrist OR hand OR finger OR thumb OR limb OR limbs OR extremity OR extremities)) OR ((writer OR stenographer OR typist OR keyboard OR piano OR musician OR barber OR golfer) AND (dystonia OR cramp))

\section{AND}

Intervention/Treatment:

Botox OR botulinum OR Meditoxin OR Neuronox OR Oculinum OR OnabotulinumtoxinA OR Abobotulinumtoxina OR Evabotulinumtoxina OR Incobotulinumtoxina OR Allergan OR Azzalure OR Bocouture OR Dysport OR Vistabel OR Xeomin OR Myobloc OR NeuroBloc OR Bontoxilysin

\section{International Clinical Trials Registry Portal (ICTRP)}

Setting - Advanced Search

28 Sep 2017

Botox OR botulinum OR Meditoxin OR Neuronox OR Oculinum OR OnabotulinumtoxinA OR Abobotulinumtoxina OR Evabotulinumtoxina OR Incobotulinumtoxina OR Allergan OR Azzalure OR Bocouture OR Dysport OR Vistabel OR Xeomin OR Myobloc OR NeuroBloc OR Bontoxilysin AND dystoni* AND focal OR wrist OR hand OR finger OR thumb OR limb OR limbs OR extremity OR extremities OR writer OR stenographer OR typist OR keyboard OR piano OR musician OR barber OR golfer OR cramp* AND focal OR wrist OR hand OR finger OR thumb OR limb OR limbs OR extremity OR extremities OR writer OR stenographer OR typist OR keyboard OR piano OR musician OR barber OR golfer

Appendix B: Reasons for exclusion of full text articles

\begin{tabular}{|c|c|}
\hline First Author/Year & $\begin{array}{l}\text { Reasons for } \\
\text { Exclusion }\end{array}$ \\
\hline Contarino (2007) [18] & $\begin{array}{l}\text { Reported on a subset of participants that were also included in } \\
\text { Kruisdijk (2007) [12] }\end{array}$ \\
\hline Wissel (1996) [19] & Not a randomized controlled trial \\
\hline Jabusch (2005) [20] & Not a randomized controlled trial \\
\hline Lungu (2011) [21] & Not a randomized controlled trial \\
\hline Bares (2002) [22] & Not a randomized controlled trial \\
\hline Behari (1998) [23] & Case series \\
\hline Berg (1999) [24] & Not a randomized controlled trial \\
\hline Dashtipour (2015) [25] & Systematic review \\
\hline Grigoriu (2015) [26] & Systematic review \\
\hline Dresel (2014) [27] & Did not include botulinum toxin \\
\hline Ross (1997) [28] & Not a randomized controlled trial \\
\hline Childers (1998) [29] & Systematic review \\
\hline Cohen (1989) [30] & Not a randomized controlled trial \\
\hline Dashtipour (2008) [31] & Systematic review \\
\hline Zeuner (2013) [32] & Not a randomized controlled trial \\
\hline Djebbari (2004) [33] & Not a randomized controlled trial \\
\hline Jankovic (1993) [34] & Not a randomized controlled trial \\
\hline Schuele (2003) [35] & Not a randomized controlled trial \\
\hline Rivest (1991) [36] & Not a randomized controlled trial \\
\hline Yoshimura (1992) [37] & Trial included participants who did not have focal hand dystonia \\
\hline Chen (1999) [38] & $\begin{array}{l}\text { Participants had concurrent intervention of either } \\
\text { resting or exercising the injected muscles }\end{array}$ \\
\hline
\end{tabular}

\section{REFERENCES}

[1] Albanese A, Bhatia K, Bressman SB, et al. Phenomenology and classification of dystonia: a consensus update. Mov Disord 2013; 28(7): 863-73

[http://dx.doi.org/10.1002/mds.25475] [PMID: 23649720]

[2] Stahl CM, Frucht SJ. Focal task specific dystonia: a review and update. J Neurol 2017; 264(7): 1536-41

[http://dx.doi.org/10.1007/s00415-016-8373-z] [PMID: 28039522]

[3] Madeo G, Pisani A. Handbookof Behavioral Neuroscience.Elsevier. 2017; pp. 929-50.

[4] Pirio Richardson S, Altenmüller E, Alter K, et al. Research Priorities in Limb and Task-Specific Dystonias. Front Neurol 2017; 8: 170. [http://dx.doi.org/10.3389/fneur.2017.00170] [PMID: 28515706]

[5] Hallett M, Albanese A, Dressler D, et al. Evidence-based review and assessment of botulinum neurotoxin for the treatment of movement disorders. Toxicon 2013; 67: 94-114.

[http://dx.doi.org/10.1016/j.toxicon.2012.12.004] [PMID: 23380701]

[6] Moher D, Liberati A, Tetzlaff J, Altman DG. Preferred reporting items for systematic reviews and meta-analyses: the PRISMA statement. PLoS Med 2009; 6(7): e1000097.

[http://dx.doi.org/10.1371/journal.pmed.1000097] [PMID: 19621072]

[7] ProQuest, LLC 2008 www.refworks.com/refworks2/ [cited October 10, 2017]

[8] Covidence 2015 www.covidence.org [cited October 15, 2017]

[9] Jadad AR, Moore RA, Carroll D, et al. Assessing the quality of reports of randomized clinical trials: is blinding necessary? Control Clin Trials 1996; 17(1): 1-12.

[http://dx.doi.org/10.1016/0197-2456(95)00134-4] [PMID: 8721797]

[10] Tsui JK, Bhatt M, Calne S, Calne DB. Botulinum toxin in the 
treatment of writer's cramp: a double-blind study. Neurology 1993; 43(1): 183-5.

[http://dx.doi.org/10.1212/WNL.43.1_Part_1.183] [PMID: 8423882]

[11] Cole R, Hallett M, Cohen LG. Double-blind trial of botulinum toxin for treatment of focal hand dystonia. Mov Disord 1995; 10(4): 466-71. [http://dx.doi.org/10.1002/mds.870100411] [PMID: 7565828]

[12] Kruisdijk JJ, Koelman JH, Ongerboer de Visser BW, de Haan RJ, Speelman JD. Botulinum toxin for writer's cramp: a randomised, placebo-controlled trial and 1-year follow-up. J Neurol Neurosurg Psychiatry 2007; 78(3): 264-70.

[http://dx.doi.org/10.1136/jnnp.2005.083170] [PMID: 17185301]

[13] Mally J, Gresty M, Findley L. Assessing the impact of essential tremors on upper limb function. J Neurol 1993; 241: 54-61. [http://dx.doi.org/10.1007/BF00870673] [PMID: 8138823]

[14] Atroshi I, Breidenbach WC, McCabe SJ. Assessment of the carpal tunnel outcome instrument in patients with nerve-compression symptoms. J Hand Surg Am 1997; 22(2): 222-7.

[http://dx.doi.org/10.1016/S0363-5023(97)80155-4] [PMID: 9195418]

[15] Wissel J, Kabus C, Wenzel R, et al. Botulinum toxin in writer's cramp: objective response evaluation in 31 patients. J Neurol Neurosurg Psychiatry 1996; 61(2): 172-5.

[http://dx.doi.org/10.1136/jnnp.61.2.172] [PMID: 8708685]

[16] Straube S, Derry S, McQuay HJ, Moore RA. Enriched enrollment: definition and effects of enrichment and dose in trials of pregabalin and gabapentin in neuropathic pain. A systematic review. Br J Clin Pharmacol 2008; 66(2): 266-75.

[http://dx.doi.org/10.1111/j.1365-2125.2008.03200.x] [PMID: 18489 611]

[17] Aids to the investigation of peripheral nerve injuries.Her Majesty's stationery office. London: Her Majesty's stationery office 1941

[18] Contarino MF, Kruisdijk JJ, Koster L, Ongerboer de Visser BW, Speelman JD, Koelman JH. Sensory integration in writer's cramp: comparison with controls and evaluation of botulinum toxin effect. Clin Neurophysiol 2007; 118(10): 2195-206.

[http://dx.doi.org/10.1016/j.clinph.2007.07.004] [PMID: 17709294]

[19] Wissel J, Kabus C, Wenzel R, et al. Botulinum toxin in writer's cramp: objective response evaluation in 31 patients. J Neurol Neurosurg Psychiatry 1996; 61(2): 172-5.

[http://dx.doi.org/10.1136/jnnp.61.2.172] [PMID: 8708685]

[20] Jabusch HC, Zschucke D, Schmidt A, Schuele S, Altenmüller E. Focal dystonia in musicians: treatment strategies and long-term outcome in 144 patients. Mov Disord 2005; 20(1): 1623-6.

[http://dx.doi.org/10.1002/mds.20631] [PMID: 16078237]

[21] Lungu C, Karp BI, Alter K, Zolbrod R, Hallett M. Long-term followup of botulinum toxin therapy for focal hand dystonia: outcome at 10 years or more. Mov Disord 2011; 26(4): 750-3

[http://dx.doi.org/10.1002/mds.23504] [PMID: 21506157]

[22] Bares M, Kanovsky P, Muchova M. Writer's cramp: Lond-term treatment with botulinum toxin A. Ces Slov Neurol Neurochir 2002; 65(4): 240-4

[23] Behari M. Botulinum toxin in the treatment of writer's cramp. J Assoc Physicians India 1999; 47(7): 694-8. [PMID]: 10778589

[24] Berg D, Naumann M, Elferich B, Reiners K. Botulinum toxin and occupational therapy in the treatment of writer'scramp. NeuroRehabilitation 1999; 12(3): 169-76.

[25] Dashtipour K, Chen JJ, Walker HW, Lee MY. Systematic literature review of abobotulinumtoxinA in clinical trials for adult upper limb spasticity. Am J Phys Med Rehabil 2015; 94(3): 229-38. [http://dx.doi.org/10.1097/PHM.0000000000000208] [PMID: 25299 523]

[26] Grigoriu AI, Dinomais M, Rémy-Néris O, Brochard S. Impact of Injection Guiding Techniques on the Effectiveness of Botulinum Toxin for the Treatment of Focal Spasticity and Dystonia: A Systematic Review. Arch Phys Med Rehabil 2015; 96(11): 2067-78.e1.

[http://dx.doi.org/10.1016/j.apmr.2015.05.002] [PMID: 25982240]

[27] Dresel C, Li Y, Wilzeck V, Castrop F, Zimmer C, Haslinger B. Multiple changes of functional connectivity between sensorimotor areas in focal hand dystonia. J Neurol Neurosurg Psychiatry 2014; 85(11): 593-8.

[http://dx.doi.org/10.1136/jnnp-2013-307127] [PMID: 24706945]

[28] Ross MH, Charness ME, Sudarsky L, Logigian EL. Treatment of occupational cramp with botulinum toxin: diffusion of toxin to adjacent noninjected muscles. Muscle And Nerve 1997; 20(5): 593-8. [http://dx.doi.org/10.1002/(SICI)1097-4598(199705)20:5<593::AIDMUS8>3.0.CO;2-4] [PMID: 9140366]

[29] Childers M, Wilson D, Galate J, Smith B. Treatment of painful muscle syndromes with botulinum toxin: A review. J Back Musculoskeletal Rehabil 1998; 10(2): 89-96.

[http://dx.doi.org/10.3233/BMR-1998-10205]

[30] Cohen LG, Hallett M, Geller BD, Hochberg F. Treatment of focal dystonias of the hand with botulinum toxin injections. J Neurol Neurosurg Psychiatry 1989; 52(3): 355-63.

[http://dx.doi.org/10.1136/jnnp.52.3.355] [PMID: 2926421]

[31] Dashtipour K, Pender RA. Evidence for the effectiveness of botulinum toxin for writer's cramp. J Neural Transm (Vienna) 2008; 115(4): 653-6.

[http://dx.doi.org/10.1007/s00702-007-0868-4] [PMID: 18322638]

[32] Zeuner KE, Knutzen A, Pedack L, Hallett M, Deuschl G, Volkmann J. Botulinum neurotoxin treatment improves force regulation in writer's cramp. Parkinsonism Relat Disord 2013; 19(6): 611-6.

[http://dx.doi.org/10.1016/j.parkreldis.2013.02.011] [PMID: 23507 416]

[33] Djebbari R, du Montcel ST, Sangla S, Vidal JS, Gallouedec G, Vidailhet M. Factors predicting improvement in motor disability in writer's cramp treated with botulinum toxin. J Neurol Neurosurg Psychiatry 2004; 75(12): 1688-91.

[http://dx.doi.org/10.1136/jnnp.2003.032227] [PMID: 15548483]

[34] Jankovic J, Schwartz KS. Use of botulinum toxin in the treatment of hand dystonia $1993 ; 18(5)$ : 883-7.

[http://dx.doi.org/10.1016/0363-5023(93)90060-G]

[35] Schuele S, Lederman RJ. Focal dystonia in woodwind instrumentalists: long-term outcome. Med Probl Perform Art 2003; 18(1): 15-20.

[36] Rivest J, Lees AJ, Marsden CD. Writer's cramp: treatment with botulinum toxin injections. Mov Disord 1991; 6(1): 55-9. [http://dx.doi.org/10.1002/mds.870060110] [PMID: 2005922]

[37] Yoshimura DM, Aminoff MJ, Olney RK. Botulinum toxin therapy for limb dystonias. Neurology 1992; 42(3 Pt 1): 627-30.

[http://dx.doi.org/10.1212/WNL.42.3.627] [PMID: 1549227]

[38] Chen R, Karp BI, Goldstein SR, Bara-Jimenez W, Yaseen Z, Hallett M. Effect of muscle activity immediately after botulinum toxin injection for writer's cramp. Mov Disord 1999; 14(2): 307-12. [http://dx.doi.org/10.1002/1531-8257(199903)14:2<307::AID-MDS10 16>3.0.CO;2-3] [PMID: 10091625]

(C) 2019 Ashworth et al.

This is an open access article distributed under the terms of the Creative Commons Attribution 4.0 International Public License (CC-BY 4.0), a copy of which is available at: (https://creativecommons.org/licenses/by/4.0/legalcode). This license permits unrestricted use, distribution, and reproduction in any medium, provided the original author and source are credited. 